Brit. J. vener. Dis. (1963), 39, 266.

\title{
IMPORTANT FACTORS IN THE CONTROL OF SYPHILIS*
}

\author{
BY \\ F. FÖLDVÁRI AND S. KÁROLYI \\ Budapest, Hungary
}

At the London conference of the I.U.V.D.T. in 1959 we described the results of our campaign against syphilis (Földvári and Károlyi, 1960). Apart from minor fluctuations, we have since succeeded in maintaining the advantageous position then reported. A general survey of the past and present situation is shown in Table $\mathrm{I}$.

TABLE I

CASES OF EARLY SYPHILIS, 1947-62

\begin{tabular}{c|c|c|c}
\hline Year & No. of Cases & Year & No. of Cases \\
\hline 1947 & 15,061 & 1955 & 58 \\
1948 & 9,851 & 1956 & 37 \\
1949 & 4,477 & 1957 & 18 \\
1950 & 4,428 & 1958 & 46 \\
1951 & 1,708 & 1959 & 6 \\
1952 & 1,085 & 1960 & 2 \\
1953 & 426 & 1961 & 32 \\
1954 & 126 & 1962 & 2 \\
\hline
\end{tabular}

The fluctuations in 1958 and 1961 were due to serial infections caused by certain promiscuous persons before the detection of their disease. These small epidemics were encouraged by the fact that contact-tracing could not detect the infectious persons quickly enough. An example of the chain-like spread of infection is illustrated in the Figure (opposite), which shows that thirteen direct infections in 28 contacts at risk were caused by one infected person, and that from five of these thirteen a further twelve serial infections were detected, making 25 cases in all.

In the evaluation of the different methods of control, primary importance is attached to direct contact-tracing, and also to the follow-up examination of persons at risk in the families and neighbourhood of infected persons. Screening examinations are also necessary, but their usefulness lies mainly in the detection of latent cases and in the prophylaxis of prenatal syphilis.

\footnotetext{
* Paper read at M.S.S.V.D. meeting in Copenhagen, June 7, 1963.
}

A short period of hospitalization for penicillin treatment during the time of infectivity followed by appropriate out-patient treatment to prevent relapses is important. Our results with penicillin in the course of 13 years, were recently reported at the congress in Zürich.

\section{Tracing of Sex Contacts}

In Hungary direct contact-tracing is carried out by the dispensaries for venereal diseases, coordinated since 1953 by a central contact-tracing organization. The improvement in our results is shown in the annual ratio of detected infectious contacts related to recent cases, expressed as a percentage (Table II).

TABLE II

RESULTS OF CONTACT-TRACING, 1953-62

\begin{tabular}{|c|c|c|}
\hline Year & Percentage & Contacts Traced \\
\hline $\begin{array}{l}1953 \\
1954 \\
1955 \\
1956 \\
1957 \\
1958 \\
1959 \\
1960 \\
1961 \\
1962\end{array}$ & & $\begin{array}{r}44 \\
45 \\
51 \\
22 \\
76 \\
78 \\
50 \\
100 \\
53 \\
0\end{array}$ \\
\hline
\end{tabular}

In 1962, the contacts of two recent cases could not be detected because the infections had been acquired abroad. Effective international co-operation on a large scale therefore seems desirable, and our experience with neighbouring countries has shown that co-operation of this kind is very successful.

\section{Screening Examinations}

In the screening examinations we have employed a rapid lipoidal precipitation reaction, and the positive cases have been verified by history-taking, clinical examination, and further serological investigation, including the Nelson test. 


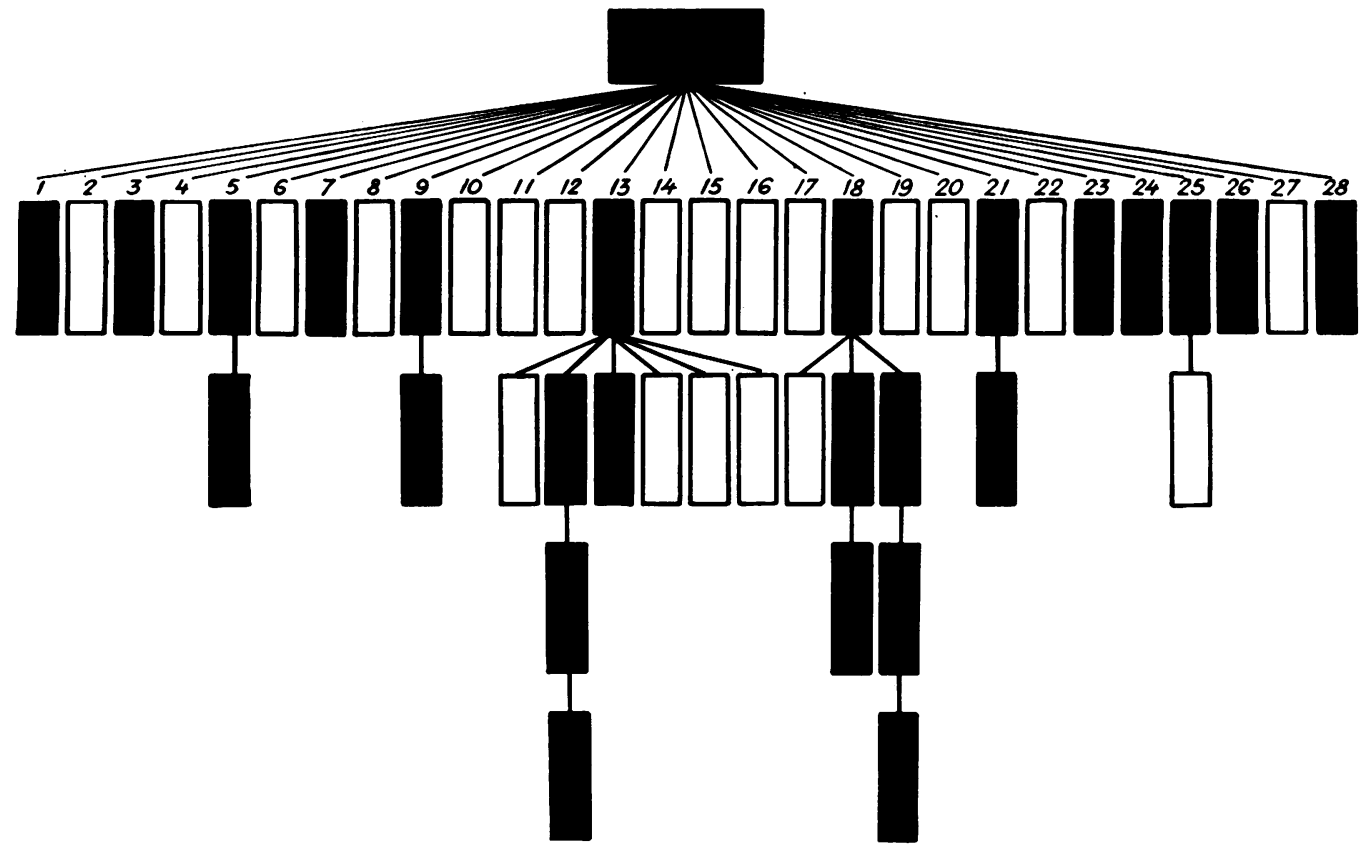

FIGURE.-Spread of infection from one case of syphilis to 25 other persons.

The number of screening examinations for syphilis and the decrease in positive cases so revealed since 1952 are shown in Table III, together with the rate of previously untreated cases found by screening since 1956.

TABLE III

CASES REVEALED BY SCREENING EXAMINATIONS, 1952-62

\begin{tabular}{c|c|c|c}
\hline Year & $\begin{array}{c}\text { No. of Screening } \\
\text { Examinations }\end{array}$ & $\begin{array}{c}\text { Positivity Rate } \\
\text { (Percentage) }\end{array}$ & $\begin{array}{c}\text { Percentage } \\
\text { Untreated } \\
\text { Cases }\end{array}$ \\
\hline 1952 & 506,807 & $2 \cdot 0$ & - \\
1953 & 635,950 & $1 \cdot 5$ & - \\
1954 & 615,580 & $1 \cdot 02$ & - \\
1955 & 700,911 & $0 \cdot 79$ & $0 \cdot 22$ \\
1956 & 585,067 & $0 \cdot 93$ & $0 \cdot 30$ \\
1957 & 574,126 & $0 \cdot 86$ & $0 \cdot 26$ \\
1958 & 584,922 & $0 \cdot 87$ & $0 \cdot 19$ \\
1959 & 646,045 & $0 \cdot 50$ & $0 \cdot 13$ \\
1960 & 657,598 & $0 \cdot 46$ & $0 \cdot 12$ \\
1961 & 729,266 & $0 \cdot 48$ & $0 \cdot 13$ \\
1962 & 634,508 & $0 \cdot 67$ & \\
\hline
\end{tabular}

Well-organized maternity dispensaries on a national scale are of particular importance in the prevention of congenital syphilis, and the venereal and maternity dispensaries are co-operating in the evaluation of serological tests. Pregnant women, even if adequately treated in the past and regarded as cured, receive two courses of penicillin during their first two pregnancies and the favourable results thereby achieved are reflected in Table IV.

TABLE IV

CASES OF CONGENITAL SYPHILIS, 1952-62

\begin{tabular}{c|c|c}
\hline & \multicolumn{2}{|c}{ Age (yrs) } \\
\cline { 2 - 3 } Year & Under 1 & 1 to 2 \\
\hline 1952 & 51 & 80 \\
1953 & 14 & 55 \\
1954 & 8 & 34 \\
1955 & 4 & 15 \\
1956 & 3 & 6 \\
1957 & 3 & 3 \\
1958 & 3 & 2 \\
1959 & 1 & 4 \\
1960 & 1 & 4 \\
1961 & 3 & 1 \\
1962 & 3 & 5 \\
\hline
\end{tabular}

In spite of these good results we are maintaining the campaign energetically, as syphilis cannot yet be regarded as eliminated, and only thus can a satisfactory degree of control be preserved.

\section{Summary}

The incidence of early syphilis in Hungary has decreased from 15,061 cases in 1947 to two in 
1962, and that of congenital syphilis from 131 in 1952 to eight in 1962. The success of contact-tracing and screening examinations is described, and an account is given of the minor epidemics which may originate from one untraced infected person.

\section{REFERENCE}

Földvári, F., and Károlyi, S. (1960). Brit. J. vener. Dis., $36,140$.

\section{Le contrôle de la syphilis}

RÉSUMÉ

En Hongrie le nombre de cas de syphilis précoce diminua de 15.061 en 1947 à deux en 1962, et celui de cas de syphilis congénitale de 131 en 1952 à huit en 1962.

On décrit le succès obtenu par la recherche des partenaires sexuels et par les examens épidémiologiques, ainsi qu'une petite épidémie provenant d'un seul cas non dépisté. 